\title{
CALCIUM SUPPLEMENTS FOR THE PREVENTION OF COLORECTAL ADENOMAS
}

\author{
J.A. Baron, M.D., M. Beach, M.D., Ph.D., J.S. Mandel, Ph.D., R.U. van Stolk, M.D., R.W. Haile, Dr.P.H., \\ R.S. SandleR, M.D., M.P.H., R. Rothstein, M.D., R.W. Summers, M.D., D.C. Snover, M.D., G.J. BeCK, Ph.D., \\ J.H. Bond, M.D., and E.R. Greenberg, M.D., for the Calcium Polyp Prevention Study Group*
}

\begin{abstract}
Background and Methods Laboratory, clinical, and epidemiologic evidence suggests that calcium may help prevent colorectal adenomas. We conducted a randomized, double-blind trial of the effect of supplementation with calcium carbonate on the recurrence of colorectal adenomas. We randomly assigned 930 subjects (mean age, 61 years; 72 percent men) with a recent history of colorectal adenomas to receive either calcium carbonate $(3 \mathrm{~g}[1200 \mathrm{mg}$ of elemental calcium] daily) or placebo, with follow-up colonoscopies one and four years after the qualifying examination. The primary end point was the proportion of subjects in whom at least one adenoma was detected after the first follow-up endoscopy but up to (and including) the second follow-up examination. Risk ratios for the recurrence of adenomas were adjusted for age, sex, lifetime number of adenomas before the study, clinical center, and length of the surveillance period.
\end{abstract}

Results The subjects in the calcium group had a lower risk of recurrent adenomas. Among the 913 subjects who underwent at least one study colonoscopy, the adjusted risk ratio for any recurrence of adenoma with calcium as compared with placebo was 0.85 (95 percent confidence interval, 0.74 to $0.98 ; \mathrm{P}=0.03$ ). The main analysis was based on the 832 subjects (409 in the calcium group and 423 in the placebo group) who completed both follow-up examinations. At least one adenoma was diagnosed between the first and second follow-up endoscopies in 127 subjects in the calcium group (31 percent) and 159 subjects in the placebo group (38 percent); the adjusted risk ratio was 0.81 (95 percent confidence interval, 0.67 to 0.99 ; $\mathrm{P}=0.04$ ). The adjusted ratio of the average number of adenomas in the calcium group to that in the placebo group was 0.76 (95 percent confidence interval, 0.60 to $0.96 ; P=0.02$ ). The effect of calcium was independent of initial dietary fat and calcium intake.

Conclusions Calcium supplementation is associated with a significant - though moderate — reduction in the risk of recurrent colorectal adenomas. ( $N$ Engl J Med 1999;340:101-7.)

(C)1999, Massachusetts Medical Society.

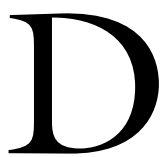
IETARY patterns have repeatedly been associated with the risk of colorectal neoplasia: a diet rich in vegetables and fruits is associated with a lower risk, whereas intake of animal fat and red meat seems to increase risk. ${ }^{1}$ The underlying mechanisms are not clear, but the changes in risk may in part be due to alterations in bile acids, which are carcinogenic in animal models. ${ }^{2}$
Newmark and colleagues ${ }^{3}$ proposed that calcium binds bile acids in the bowel lumen, inhibiting their proliferative and carcinogenic effects. In support of this hypothesis, studies in animals have indicated a protective effect of dietary calcium on bile-induced mucosal damage and experimental bowel carcinogenesis. ${ }^{4,5}$ However, the results of epidemiologic research have been inconsistent; in some studies a decreased risk of colorectal cancer was associated with calcium intake, whereas in others no association was found. 6,7 Mixed results have also been reported regarding largebowel adenomas, ${ }^{6,7}$ which are likely precursors of most colorectal cancers. ${ }^{8}$

To clarify the effect of calcium intake on colorectal carcinogenesis, we conducted a clinical study of the effect of supplementation with calcium carbonate on the risk of recurrence of colorectal adenomas. We hypothesized that subjects randomly assigned to receive calcium would have a reduced risk of recurrent adenomas as well as reduced numbers of adenomas.

\section{METHODS}

The Calcium Polyp Prevention Study involved six clinical centers: the Cleveland Clinic Foundation, Dartmouth-Hitchcock Medical Center, the University of Southern California-Southern California Permanente Medical Group, the University of Iowa, the University of Minnesota, and the University of North Carolina. Dartmouth was the coordinating center, and the University of Minnesota was the pathology center. Human-subjects committees at each center approved the study protocol; an independent data and safety monitoring committee reviewed the study twice a year.

From the Departments of Medicine (J.A.B., R.R.), Community and Family Medicine (J.A.B.), and Anesthesia (M.B.) and the Norris Cotton Cancer Center (E.R.G.), Dartmouth-Hitchcock Medical Center, Lebanon, N.H.; the Veterans Affairs Medical Center, White River Junction, Vt. (M.B.); the Department of Environmental and Occupational Health, School of Public Health and School of Medicine (J.S.M.), and the Departments of Pathology (D.C.S.) and Medicine (J.H.B.), School of Medicine, University of Minnesota, and the Veterans Affairs Medical Center (J.H.B.), Minneapolis; the Center for Colon Polyps and Colon Cancer, Department of Gastroenterology (R.U.S.), and the Department of Biostatistics and Epidemiology (G.J.B.), Cleveland Clinic Foundation, Cleveland; the Department of Preventive Medicine, University of Southern California School of Medicine, Los Angeles (R.W.H.); the Department of Medicine, University of North Carolina, Chapel Hill, N.C. (R.S.S.); the James A. Clifton Center for Digestive Diseases, Department of Internal Medicine, University of Iowa College of Medicine, Iowa City (R.W.S.); and the Department of Pathology, Fairview Southdale Hospital, Minneapolis (D.C.S.). Address reprint requests to Dr. Baron at 7927 Rubin Bldg., Dartmouth-Hitchcock Medical Center, 1 Medical Center Dr., Lebanon, NH 03756.

Other authors were H. Frankl, M.D., Department of Internal Medicine, Southern California Permanente Group, Los Angeles; and L. Pearson, M.Phil., Department of Community and Family Medicine, DartmouthHitchcock Medical Center, Lebanon, N.H.

*Additional study investigators are listed in the Appendix 


\section{Recruitment and Randomization}

Staff at each clinical center monitored colonoscopy and pathology records at associated endoscopy units to identify subjects who had at least one histologically confirmed large-bowel adenoma removed within three months before recruitment and whose entire largebowel mucosa was subsequently examined and judged free of polyps. Eligible subjects were less than 80 years old, in good health, and without a history of familial polyposis, invasive large-bowel cancer, malabsorption syndromes, or any condition that might be worsened by supplemental calcium. Our goal was for 860 subjects to undergo randomization in order for the study to have 80 percent power to detect a 25 percent reduction in the recurrence of adenomas.

We reviewed data on 2918 apparently eligible subjects. We were unable to contact 223,1066 declined to participate, 510 were found to be ineligible, and 1 did not enroll for unknown reasons. After written informed consent had been obtained, the remaining 1118 subjects began a three-month placebo run-in period to assess their adherence to the study regimen of one tablet twice a day with meals. At the end of the run-in period, 930 subjects had taken at least 80 percent of their prescribed tablets, wished to continue the study, and were considered appropriate for randomization. We assigned these subjects to calcium or placebo using computergenerated random numbers, blocked according to study center. The study tablets contained a total of $3 \mathrm{~g}$ of calcium carbonate (1200 mg of elemental calcium) or an identical-appearing cellulose-sucrose placebo. The trial was double-blind: neither subjects nor study staff were aware of the treatment assignments.

\section{Study Protocol}

The subjects underwent two follow-up colonoscopies as part of their routine clinical care, usually by the same physician who had conducted the initial examination. The first follow-up examination was planned for approximately 1 year after the qualifying colonoscopy (about 9 months after randomization), and the second follow-up examination was planned for 36 months after that. Large-bowel endoscopy was otherwise discouraged unless clinically indicated (e.g., for rectal bleeding). Follow-up examinations were considered adequate if the entire large-bowel mucosa was visualized and no polyps remained at the end of the procedure. We designated the time from randomization to the first followup examination as the first study interval, and the period following the first follow-up examination and through the second as the second study interval (the main risk period).

At each colonoscopy, the endoscopist recorded the size and location of all mucosal lesions, using standard clinical technique. According to the protocol, all polyps were removed and examined histologically at the clinical center and by the study pathologist, who classified the polyps as neoplastic (adenomas) or non-neoplastic (e.g., hyperplastic polyps or lymphoid follicles). The study pathologist also reviewed polyps detected by the qualifying endoscopic examination for a sample of 25 percent of the subjects. The study pathologist and the clinical center agreed as to presence or absence of neoplasia in 2349 of the 2541 specimens reviewed (92 percent). In cases of disagreement, we accepted the study pathologist's diagnosis.

At enrollment and at the time of each of the two follow-up colonoscopies, we obtained specimens of venous blood in mineralfree tubes. Serum was initially stored at $-20^{\circ} \mathrm{C}$ or below, pending shipment to Dartmouth for storage at $-70^{\circ} \mathrm{C}$ until analysis. At enrollment and at the end of the study, we also assessed the subjects' diet with a validated food-frequency questionnaire. ${ }^{9}$ Every six months, we sent questionnaires to the subjects regarding their adherence to study treatment; their use of medications, over-thecounter drugs, and nutritional supplements; and the occurrence of symptoms, illnesses, and hospitalizations. Recruitment began in November 1988 and ended in April 1992. Follow-up ended in December 1996.

\section{End Points}

The primary outcome measure was the proportion of subjects in whom at least one adenoma was detected during the second study interval - that is, after the first follow-up colonoscopy, up to and including the second follow-up examination (including adenomas detected during interim endoscopies). This end point provided for the removal of adenomas overlooked at the qualifying colonoscopy (thus minimizing the numbers of polyps present at the start of the main risk period) and allowed for a latent period of calcium action. If a subject did not undergo the followup examinations as planned, we used the two clinically indicated colonoscopies at least one year apart that provided the longest follow-up interval.

\section{Statistical Analysis}

For our statistical analyses, we compared proportions using Fisher's exact test and measured data using t-tests or rank tests. ${ }^{10}$ Our main analysis considered two related outcomes: whether subjects in the two treatment groups had different probabilities of having at least one adenoma, and whether the average numbers of adenomas in the two groups differed. To address the first question, we used overdispersed log-linear quasi-likelihood models programmed in SPlus (MathSoft, Seattle) to provide unadjusted and adjusted estimates and confidence intervals for the relative risk of at least one recurrent adenoma. ${ }^{11}$ Similar models (with variance proportional to the mean) were used to analyze the ratios of the average number of adenomas in the two treatment groups. ${ }^{11}$

Covariates included age (as a linear term), sex, the lifetime number of adenomas before study entry, clinical center, and the length of the surveillance period. Possible interactions were considered with the use of product interaction terms. Subgroup analyses included investigation of subjects whose diets were above and below the median for the calorie-adjusted intake ${ }^{12}$ of selected nutrients. To assess possible distortions introduced by subjects who did not complete the study, we also performed sensitivity analyses by imputing patterns of recurrence for these subjects to determine outcomes that would have altered our conclusions, had they been observed. All $\mathrm{P}$ values were two-sided; $\mathrm{P}<0.05$ was taken to indicate significance.

\section{RESULTS}

A total of 930 subjects, whose characteristics are summarized in Table 1, underwent randomization; there were no significant differences between the two treatment groups in demographic characteristics, dietary patterns, or history of adenomas. The mean $( \pm S D)$ age was $61 \pm 9$ years, and 72 percent were men. Most subjects had had only one or two adenomas removed from the large bowel before entering the study. The mean estimated diameter of the largest qualifying adenoma was $0.7 \pm 0.6 \mathrm{~cm}$; in the sample sent for pathological review, 99 percent of the specimens had mild or moderate atypia. The mean estimated daily dietary intake of calcium at study entry was similar in the two study groups and was less than three quarters of the amount later provided in the form of supplements by the study intervention. Fewer than 3 percent of the subjects were taking calcium supplements at the start of the trial; all agreed to discontinue them during the study.

Of the 930 subjects who underwent randomization, 832 (89 percent) completed two follow-up colonoscopies (Table 2 ). We could not include 98 subjects (43 in the placebo group and 55 in the calcium group) in the main analyses: 47 died, 25 no longer wished to participate, 18 could not be examined because they were too ill or had moved, and 8 dropped 
Table 1. Base-Line Characteristics of the 930 Subjects.*

\begin{tabular}{|c|c|c|c|c|}
\hline \multirow[t]{2}{*}{ Characteristic } & \multicolumn{2}{|c|}{$\begin{array}{l}\text { All RANDomized } \\
\text { SUBJects }\end{array}$} & \multicolumn{2}{|c|}{$\begin{array}{l}\text { SUBJECTS WHO } \\
\text { COMPLETED STUDY }\end{array}$} \\
\hline & $\begin{array}{l}\text { PLACEBO } \\
(\mathrm{N}=466)\end{array}$ & $\begin{array}{l}\text { CALCIUM } \\
(\mathrm{N}=464)\end{array}$ & $\begin{array}{l}\text { PLACEBO } \\
(\mathrm{N}=423)\end{array}$ & $\begin{array}{l}\text { CALCIUM } \\
(\mathrm{N}=409)\end{array}$ \\
\hline \multicolumn{5}{|l|}{ Sex - no. $(\%)$} \\
\hline Male & $327(70)$ & $345(74)$ & $296(70)$ & $302(74)$ \\
\hline Female & $139(30)$ & $119(26)$ & $127(30)$ & $107(26)$ \\
\hline Age - yr & $61.0 \pm 9.1$ & $61.0 \pm 9.1$ & $60.9 \pm 9.0$ & $60.7 \pm 8.8$ \\
\hline \multicolumn{5}{|l|}{ Study center - no. $(\%)$} \\
\hline Cleveland Clinic & $72(15)$ & $71(15)$ & $70(17)$ & $67(16)$ \\
\hline Dartmouth-Hitchcock & $85(18)$ & $72(16)$ & $76(18)$ & $62(15)$ \\
\hline University of Iowa & $87(19)$ & $86(19)$ & $79(19)$ & $74(18)$ \\
\hline University of Minnesota & $81(17)$ & $85(18)$ & $75(18)$ & $72(18)$ \\
\hline University of North Carolina & $64(14)$ & $59(13)$ & $56(13)$ & $51(12)$ \\
\hline University of Southern California & $77(17)$ & $91(20)$ & $67(16)$ & $83(20)$ \\
\hline No. of prior adenomas $\dagger$ & $2.6 \pm 2.8$ & $2.4 \pm 2.5$ & $2.6 \pm 2.9$ & $2.5 \pm 2.6$ \\
\hline \multicolumn{5}{|l|}{ Daily dietary intakef } \\
\hline Calories - kcal & $2010 \pm 756$ & $2040 \pm 761$ & $2011 \pm 742$ & $2032 \pm 756$ \\
\hline Fat $-\mathrm{g}$ & $88.1 \pm 42.9$ & $87.2 \pm 41.3$ & $87.9 \pm 42.4$ & $86.1 \pm 40.5$ \\
\hline Fiber $-\mathrm{g}$ & $16.2 \pm 7.8$ & $16.6 \pm 8.0$ & $16.4 \pm 8.0$ & $16.7 \pm 8.0$ \\
\hline Calcium - mg & $865 \pm 423$ & $889 \pm 451$ & $866 \pm 421$ & $893 \pm 451$ \\
\hline $\begin{array}{l}\text { Taking supplemental calcium } \\
\text { - no. }(\%)\end{array}$ & $13(3)$ & $11(2)$ & $12(3)$ & $11(3)$ \\
\hline
\end{tabular}

*Plus-minus values are means \pm SD. None of the differences between groups were significant. Because of rounding, percentages do not always total 100 .

†The lifetime number of colorectal adenomas found and removed before randomization is given.

$\ddagger$ Dietary information was missing for 10 subjects in the placebo group and 13 in the calcium group.

Table 2. Numbers of Study Subjects Who Completed the Study Examinations.*

\begin{tabular}{|c|c|c|}
\hline SUBJects & PLACEBo $(\mathrm{N}=466)$ & Calcium $(\mathrm{N}=464)$ \\
\hline Died - no. (\%) & $22(5)$ & $25(5)$ \\
\hline \multicolumn{3}{|l|}{ Dropped out - no. (\%) } \\
\hline Lost interest & $11(2)$ & $14(3)$ \\
\hline Ill or moved & $8(2)$ & $10(2)$ \\
\hline Other or unknown reasons & $2(<1)$ & $6(1)$ \\
\hline Received first follow-up colonoscopy — no. (\%) & $459(98)$ & $454(98)$ \\
\hline First surveillance interval - mo & $13 \pm 0.2$ & $14 \pm 0.3$ \\
\hline $\begin{array}{l}\text { Interim endoscopy during first surveillance } \\
\text { interval - no. }(\%)\end{array}$ & $5(1)$ & $14(3) \dagger$ \\
\hline Inadequate first follow-up colonoscopy - no. (\%) & $21(5)$ & $22(5)$ \\
\hline Received second follow-up colonoscopy - no. (\%) & $423(91)$ & $409(88)$ \\
\hline Second surveillance interval - mo & $37 \pm 0.2$ & $37 \pm 0.2$ \\
\hline $\begin{array}{l}\text { Interim endoscopy during second surveillance } \\
\text { interval - no. (\%) }\end{array}$ & $51(12)$ & $35(9)$ \\
\hline Inadequate second follow-up colonoscopy - no. (\%) & $29(7)$ & $35(9)$ \\
\hline
\end{tabular}

*Plus-minus values are means \pm SE.

$\dagger \mathrm{P}=0.04$ for the difference between groups.

out for unknown reasons. In addition to the studymandated colonoscopies, an interval colonoscopy or sigmoidoscopy was performed during the main risk period (second study interval) in 86 subjects. The proportions of subjects with inadequate study colonoscopies or with interim endoscopies did not differ significantly between the treatment groups (Table 2).

Self-reported adherence to the study regimen grad- ually declined during the trial (Table 3 ). Nevertheless, even during the fourth year, over 80 percent of the subjects took the study agents 90 to 100 percent of the time, and a further 7 percent took them 50 to 89 percent of the time. Use of supplemental calcium was reported at least once by only 19 subjects ( 2 percent) during the study ( 9 in the placebo group and 10 in the calcium group). 
Table 3. Self-Reported Adherence to Study Treatment, According to Treatment Assignment and Study Year.*

\begin{tabular}{ccc}
\hline $\begin{array}{c}\text { YeAR AND } \\
\text { PERCENTAGE } \\
\text { OF TABLETS TAKEN }\end{array}$ & $\begin{array}{c}\text { PLACEBO } \\
\text { (N=466) }\end{array}$ & $\begin{array}{c}\text { Calcium } \\
\text { (N=464) }\end{array}$ \\
\multicolumn{2}{c}{ number (percent) } \\
Year 1 & & \\
$90-100$ & $409(88)$ & $393(85)$ \\
$50-89$ & $42(9)$ & $50(11)$ \\
$<50$ & $14(3)$ & $18(4)$ \\
Year 2 & $373(81)$ & $371(82)$ \\
$90-100$ & $52(11)$ & $44(10)$ \\
$50-89$ & $38(8)$ & $40(9)$ \\
$<50$ & $377(83)$ & $358(80)$ \\
Year 3 & $33(7)$ & $39(9)$ \\
$90-100$ & $44(10)$ & $52(12)$ \\
$50-89$ & $358(82)$ & $346(79)$ \\
$<50$ & $31(7)$ & $34(8)$ \\
Year 4 & $49(11)$ & $58(13)$ \\
$90-100$ & & \\
$50-89$ & & \\
$<50$ & &
\end{tabular}

*Numbers of subjects do not sum to 930 because of dropouts, deaths, and missing data. Because of rounding, percentages do not always total 100 .

Among the 832 subjects who completed the study, at least one colorectal adenoma was diagnosed during the main risk period (the second study interval) in 127 subjects in the calcium group (31 percent) and 159 subjects in the placebo group (38 percent) (Table 4). The mean size of the largest adenoma was the same in the two groups $(0.4 \mathrm{~cm} ; \mathrm{P}=0.43)$, but more adenomas were found in the placebo group (mean number per patient, 0.73 vs. $0.55 ; \mathrm{P}=0.03$ ). The unadjusted risk ratio for having at least one adenoma in the calcium group as compared with the placebo group was 0.83 (95 percent confidence interval, 0.68 to $1.00 ; \mathrm{P}=0.05)$; after adjustment the risk ratio was 0.81 (95 percent confidence interval, 0.67 to $0.99 ; \mathrm{P}=0.04)$. The unadjusted ratio of the average number of adenomas in the calcium group to that in the placebo group was 0.75 (95 percent confidence interval, 0.58 to $0.97 ; \mathrm{P}=0.03)$; after adjustment it was 0.76 (95 percent confidence interval, 0.60 to $0.96 ; \mathrm{P}=0.02)$. During the main risk period, invasive large-bowel cancer was found in four subjects (three in the placebo group and one in the calcium group), but no adenomas with severe atypia were found ( $\mathrm{P}=0.62$ for the difference in the proportions with severe atypia or cancer). Analysis of adenomas detected at the second follow-up examination (excluding findings on interval endoscopies) showed similar results (Table 4).

A similar effect of calcium was found during the first study interval. Among the subjects who completed the trial, at least one adenoma was found in the period up to and including the first follow-up examination in 103 subjects in the calcium group ( 25 percent) and 138 subjects in the placebo group (33 percent) (Table 4). The unadjusted risk ratio for at least one adenoma in this early interval was 0.77 (95 percent confidence interval, 0.62 to $0.96 ; \mathrm{P}=0.02$ ); the unadjusted ratio of the average numbers of adenomas was 0.73 (95 percent confidence interval, 0.54 to $0.97 ; \mathrm{P}=0.03)$. These estimates were virtually unchanged after multivariate adjustment. Analysis of adenomas detected at the first follow-up examination

Table 4. Outcomes with Respect to Recurrence of Adenomas.

\begin{tabular}{|c|c|c|c|c|c|c|}
\hline \multirow[t]{2}{*}{ SubJeCts* } & \multicolumn{2}{|c|}{ Placebo } & \multicolumn{2}{|c|}{ Calcium } & \multirow[t]{2}{*}{$\begin{array}{c}\text { ADJUSTED } \\
\text { RELATIVE RISK } \\
\text { OF } \geqslant 1 \text { ADENOMA } \\
(95 \% \mathrm{Cl}) \dagger\end{array}$} & \multirow[t]{2}{*}{$\begin{array}{l}\text { AdJusted Ratio of } \\
\text { MEAN No. OF } \\
\text { ADENOMAS } \\
(95 \% \mathrm{Cl}) \dagger\end{array}$} \\
\hline & $\begin{array}{l}\text { PERCENTAGE WITH } \\
\quad \geqslant 1 \text { ADENOMA }\end{array}$ & $\begin{array}{l}\text { MEAN NO. OF } \\
\text { ADENOMAS }\end{array}$ & $\begin{array}{l}\text { PERCENTAGE WITH } \\
\quad \geqslant 1 \text { ADENOMA }\end{array}$ & $\begin{array}{l}\text { MEAN NO. OF } \\
\text { ADENOMAS }\end{array}$ & & \\
\hline \multicolumn{7}{|l|}{ Completed study } \\
\hline First study interval & 33 & 0.60 & 25 & 0.43 & $0.78(0.63-0.96)$ & $0.75(0.58-0.96)$ \\
\hline First study examination & 33 & 0.59 & 24 & 0.40 & $0.75(0.61-0.94)$ & $0.70(0.54-0.89)$ \\
\hline Second study interval & 38 & 0.73 & 31 & 0.55 & $0.81(0.67-0.99)$ & $0.76(0.60-0.96)$ \\
\hline Second study examination & 36 & 0.62 & 30 & 0.51 & $0.83(0.68-1.01)$ & $0.83(0.65-1.05)$ \\
\hline First or second study interval & 52 & 1.32 & 45 & 0.98 & $0.85(0.74-0.98)$ & $0.75(0.62-0.90)$ \\
\hline \multicolumn{7}{|l|}{ Had at least one endoscopy } \\
\hline First or second study interval & 51 & 1.26 & 43 & 0.92 & $0.85(0.74-0.98)$ & $0.75(0.63-0.90)$ \\
\hline Study examinations & 50 & 1.15 & 42 & 0.86 & $0.84(0.73-0.97)$ & $0.77(0.64-0.91)$ \\
\hline
\end{tabular}

*The first study interval was from randomization to the first follow-up colonoscopy; the second study interval (the main risk period) was after the first follow-up colonoscopy and up to and including the second follow-up colonoscopy. Four hundred twenty-three subjects in the placebo group and 409 in the calcium group completed the study; 459 and 454, respectively, had at least one endoscopy.

†The risk ratio for at least one adenoma and the ratio of the mean numbers of adenomas in the calcium group as compared with the placebo group are given. Both estimates have been adjusted for age, sex, clinical center, number of previous adenomas, and length of follow-up. CI denotes confidence interval. 
yielded similar findings. At or before the first followup examination, invasive cancer was found in four subjects (two in the calcium group and two in the placebo group), and an adenoma with severe atypia was removed from one subject in each group.

A total of 913 subjects underwent at least one study colonoscopy. The unadjusted risk ratio for having at least one adenoma after randomization was 0.85 (95 percent confidence interval, 0.74 to $0.98 ; \mathrm{P}=0.03$ ); the corresponding ratio of the average numbers of adenomas was 0.74 (95 percent confidence interval, 0.59 to $0.92 ; \mathrm{P}<0.001)$. Restriction of the analysis to adenomas detected at study follow-up examinations and adjustment for age, clinical center, sex, length of the surveillance period, and number of previous adenomas left these estimates substantially unchanged (Table 4).

We also assessed whether the effect of calcium supplementation differed according to the size or location of the adenomas. During the second study interval, an adenoma $0.5 \mathrm{~cm}$ or greater in diameter was found in 120 subjects $(63$ in the placebo group and 57 in the calcium group); the unadjusted risk ratio for having at least one adenoma of this size was 0.87 (95 percent confidence interval, 0.63 to $1.21 ; \mathrm{P}=0.70$ ). In 166 subjects, the largest adenoma was less than $0.5 \mathrm{~cm}$ in diameter (96 in the placebo group and 70 in the calcium group); the corresponding unadjusted risk ratio was 0.75 (95 percent confidence interval, 0.57 to $0.98 ; \mathrm{P}=0.03)$. During the second interval, 144 subjects had at least one adenoma in the splenic flexure or more distally, and 200 had at least one adenoma proximal to the splenic flexure. Calcium had a similar effect on the recurrence of adenoma in both regions of the bowel (data not shown).

The sensitivity analysis suggested that it is extremely unlikely that the outcomes of the 98 subjects who did not complete the study would have nullified our findings had they been able to be included. Among these subjects, recurrent adenomas would have had to be at least twice as frequent in the calcium group as in the placebo group to eliminate the statistical significance of the overall effect of calcium.

There was no evidence of modification of the effect of calcium by age, sex, or base-line dietary intake of calcium, fat, or fiber (data not shown). The effect of calcium was nonsignificantly stronger among subjects who reported taking all their study agents and among those who did not report any use of aspirin or other nonsteroidal antiinflammatory drugs (data not shown).

Medical symptoms and complications were not associated with treatment assignment. Similar proportions of subjects in the calcium and placebo groups were hospitalized for any reason, were hospitalized with cancer, or stopped treatment because of perceived side effects (Table 5). The frequency of digestive symptoms (including constipation) did not dif- fer substantially between the two treatment groups. Two subjects assigned to calcium and one assigned to placebo were found to have definite or probable urinary stones during the study.

\section{DISCUSSION}

In this randomized, clinical trial, assignment to calcium supplementation was associated with a significant - though moderate - reduction in the risk of recurrent adenomas. The reduced risk became apparent as early as the first colonoscopic follow-up, after approximately nine months of treatment. There was no indication of a greater effect among subjects with a low base-line dietary intake of calcium or a high intake of fat. The intervention was well accepted and without major toxicity.

Epidemiologic data regarding the association between dietary calcium and the risk of colorectal cancer have varied considerably but in the aggregate are consistent with the effect we observed.6,7 Many studies $^{13-18}$ found at least suggestions of an inverse association, but others found no relation ${ }^{19,20}$ or even the possibility of an increased risk with higher intake. ${ }^{21,22}$ The results of investigations of calcium intake and the risk of colorectal adenomas have also been conflicting, ${ }^{20,23-25}$ as have those of studies that considered calcium supplementation separately. ${ }^{16,21,26}$

These mixed findings may reflect the difficulties of dietary epidemiology. The effects of calcium intake are likely to be confounded by factors such as intake of calories, dietary fat, and phosphate and perhaps use of vitamin and mineral supplements, aspirin, or other agents with anticarcinogenic effects. Moreover, the measurement error inherent in dietary assessment would tend to obscure any association between calcium intake and the risk of neoplasia. ${ }^{12}$

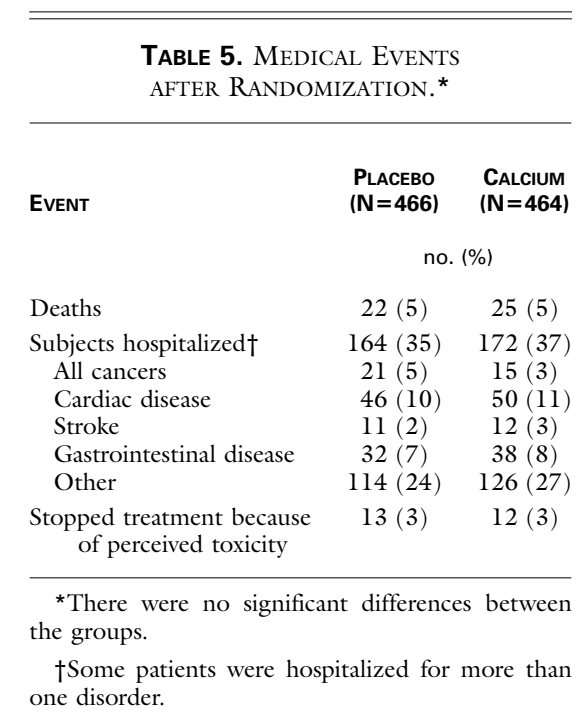

Volume 340 Number 2 
Extensive research in animals supports the existence of an antineoplastic effect of calcium in the large bowel. Calcium inhibits the mucosal injury and hyperproliferation induced by bile acids or carcinogens, ${ }^{4}$ and most studies that used high-fat diets reported a lower incidence of tumors with supplementation. ${ }^{4,5}$ Effects of calcium have been absent or less pronounced among animals fed low-fat diets. ${ }^{27,28}$ One experimental study suggested that dietary calcium particularly inhibited tumors with ras mutations, ${ }^{29}$ and a recent epidemiologic study reported similar effects. ${ }^{30}$

Previously published trials of calcium supplementation have focused on biologic markers; some of these studies have supported the hypothesis that calcium may act through precipitation of bile acids or stool fatty acids, perhaps in complexes with calcium phosphate. ${ }^{31}$ Calcium supplementation has been observed to reduce the cytotoxicity of fecal water, reduce the proportion of secondary bile acids in the bile acid pool, and reduce fecal bile acid concentrations. ${ }^{31-34}$ However, other studies have not suggested such benefits, reporting no change ${ }^{35,36}$ or an actual increase ${ }^{37,38}$ in the concentration of bile acids in the water phase of stool. The results of studies of the effect of calcium on rectal mucosal proliferation have been conflicting. $32,36,37,39-43$

Our trial focused on the recurrence of adenomas over a four-year period. Therefore, it does not directly address whether calcium supplementation affects the risk of a first adenoma or of progression to invasive cancer. Still, the similarity of risk factors for colorectal cancer, recurrent adenomas, and first adenomas ${ }^{44}$ suggests that an agent that affects early stages of neoplasia in the bowel may well have implications for more advanced neoplasia. On the other hand, our data may suggest that calcium supplementation has a weaker effect on larger adenomas than on smaller ones, a pattern consistent with a limited efficacy of supplementation in patients with more advanced neoplasia.

Other unresolved issues are the timing and persistence of the antineoplastic action of calcium. In our trial, a reduction in the risk of recurrent adenomas became evident less than a year after randomization, but the effect did not become stronger with time. Conceivably, an increasing efficacy of treatment over time was counterbalanced by decreasing compliance. Studies with longer treatment and follow-up periods are needed to clarify these issues.

Our data provide evidence that calcium carbonate may have chemopreventive activity against colorectal neoplasia. The effect we found is consistent with epidemiologic data and is supported by a large body of experimental data in humans and in animals. Since the toxicity of this simple and inexpensive agent appears to be minimal, and since it may have other benefits (e.g., reduction in the risk of osteoporosis ${ }^{45}$ ), its risk-benefit balance may be favorable. However, before a general recommendation can confidently be made, it would be desirable to confirm these findings, obtain more information about effects on actual cancers or severe dysplasia, and document the risk-benefit balance in various population groups.

Supported in part by grants (CA37287 and CA23108) from the National Institutes of Health. Calcium and placebo tablets were provided by Lederle (now Whitehall-Robins), Pearl River, N.Y.

We are indebted to the study subjects and their physicians for their cooperation and enthusiasm, and to the study coordinators at the clinical sites and the data-processing, pharmacy, and laboratory staff at the coordinating center for their efforts throughout this investigation.

\section{APPENDIX}

In addition to the authors, the Calcium Polyp Prevention Study Group included the following investigators: L.A. Mott, D.W. Nierenberg, M.M. Stevens, T. Stukel, and T.D. Tosteson (Dartmouth Medical School); D. Howell (Maine Medical Center); J. Church (Cleveland Clinic Foundation); and J. Truszkowski (University of Iowa). The study coordinators were $\mathrm{H}$. Hasson and J. Bauman (Cleveland Clinic); K. Wood (Dartmouth-Hitchcock Medical Center); B. Cheyne, R. Thompson, and D. Finke (University of Iowa); J. Blomquist and S. Waldemar (University of Minnesota); C. McAuliffe and B. Schliebe (University of North Carolina); and P. Harmon (University of Southern California). The members of the data and safety monitoring committee were S. Greenhouse (George Washington University) J. Grizzle (Fred Hutchinson Cancer Research Center), R. Hunt (McMaster University), G. Luk (Wayne State University), F.M. Giardiello (Johns Hopkins University), and W.C. Willett (Harvard University).

\section{REFERENCES}

1. Sandler RS. Epidemiology and risk factors for colorectal cancer. Gastroenterol Clin North Am 1996;25:717-35.

2. Nagengast FM, Grubben MJAL, van Munster IP. Role of bile acids in colorectal carcinogenesis. Eur J Cancer 1995;31A:1067-70.

3. Newmark HL, Wargovich MJ, Bruce WR. Colon cancer and dietary fat, phosphate, and calcium: a hypothesis. J Natl Cancer Inst 1984;72: 1323-5

4. Pence BC. Role of calcium in colon cancer prevention: experimental and clinical studies. Mutat Res 1993;290:87-95.

5. Pence BC, Buddingh F. Inhibition of dietary fat-promoted colon carcinogenesis in rats by supplemental calcium or vitamin $\mathrm{D}_{3}$. Carcinogenesis 1988;9:187-90.

6. Bergsma-Kadijk JA, van't Veer P, Kampman E, Burema J. Calcium does not protect against colorectal neoplasia. Epidemiology 1996;7:590-7.

7. Martinez ME, Willett WC. Calcium, vitamin D, and colorectal cancer: a review of the epidemiologic evidence. Cancer Epidemiol Biomarkers Prev 1998;7:163-8.

8. Hill MJ, Morson BC, Bussey HJ. Aetiology of adenoma - carcinoma sequence in large bowel. Lancet 1978;1:245-7.

9. Block G, Hartman AM, Dresser CM, Carroll MD, Gannon J, Gardner

L. A data-based approach to diet questionnaire design and testing. Am

J Epidemiol 1986;124:453-69.

10. Snedecor GW, Cochran WG. Statistical methods. 7th ed. Ames: Iowa State University Press, 1980.

11. McCullagh $P$, Nelder JA. Generalized linear models. 2nd ed. London: Chapman \& Hall, 1989.

12. Willett W. Nutritional epidemiology. New York: Oxford University Press, 1990

13. Slattery ML, Sorenson AW, Ford MH. Dietary calcium intake as a mitigating factor in colon cancer. Am J Epidemiol 1988;128:504-14.

14. Whittemore AS, Wu-Williams AH, Lee M, et al. Diet, physical activity, and colorectal cancer among Chinese in North America and China. J Natl Cancer Inst 1990;82:915-26.

15. Garland CF, Shekelle RB, Barrett-Connor E, Criqui MH, Rossof AH, Paul O. Dietary vitamin D and calcium and risk of colorectal cancer: a 19 year prospective study in men. Lancet 1985;1:307-9.

16. Bostick RM, Potter JD, Sellers TA, McKenzie DR, Kushi LH, Folsom AR. Relation of calcium, vitamin $\mathrm{D}$, and dairy food intake to incidence of colon cancer among older women: the Iowa Women's Health Study. Am J Epidemiol 1993;137:1302-17.

17. Kearney J, Giovannucci E, Rimm EB, et al. Calcium, vitamin D, and 
dairy foods and the occurrence of colon cancer in men. Am J Epidemiol 1996;143:907-17.

18. Martinez ME, Giovannucci EL, Colditz GA, et al. Calcium, vitamin $\mathrm{D}$, and the occurrence of colorectal cancer among women. J Natl Cancer Inst 1996;88:1375-82

19. Graham S, Marshall J, Haughey B, et al. Dietary epidemiology of cancer of the colon in western New York. Am J Epidemiol 1988;128:490-503.

20. Boutron MC, Faivre J, Marteau P, Couillault C, Senesse P, Quipourt V. Calcium, phosphorus, vitamin $\mathrm{D}$, dairy products and colorectal carcinogenesis: a French case-control study. Br J Cancer 1996;74:145-51

21. Kampman E, Boldbohm RA, van den Brandt PA, van 't Veer P. Fermented dairy products, calcium, and colorectal cancer in the Netherlands Cohort Study. Cancer Res 1994;54:3186-90.

22. Pritchard RS, Baron JA, Gerhardsson de Verdier M. Dietary calcium, vitamin D, and the risk of colorectal cancer in Stockholm, Sweden. Cancer Epidemiol Biomarkers Prev 1996;5:897-900.

23. Little J, Logan RFA, Hawtin PG, Hardcastle JD, Turner ID. Colorectal adenomas and diet: a case-control study of subjects participating in the Nottingham faecal occult blood screening programme. Br J Cancer 1993; 67:177-84.

24. Kampman E, Giovannucci E, van 't Veer P, et al. Calcium, vitamin D, dairy foods, and the occurrence of colorectal adenomas among men and women in two prospective studies. Am J Epidemiol 1994;139:16-29. 25. Tseng M, Murray SC, Kupper LL, Sandler RS. Micronutrients and the risk of colorectal adenomas. Am J Epidemiol 1996;144:1005-14

26. Neugut AI, Horvath K, Whelan RL, et al. The effect of calcium and vitamin supplements on the incidence and recurrence of colorectal adenomatous polyps. Cancer 1996;78:723-8.

27. McSherry CK, Cohen BI, Bokkenheuser VD, et al. Effects of calcium and bile acid feeding on colon tumors in the rat. Cancer Res 1989;49:6039-43. 28. Sitrin MD, Halline AG, Abrahams C, Brasitus TA. Dietary calcium and vitamin D modulate 1,2-dimethylhydrazine-induced colonic carcinogenesis in the rat. Cancer Res 1991;51:5608-13.

29. Llor X, Jacoby RF, Teng B-B, Davidson NO, Sitrin MD, Brasitus TA $\mathrm{K}$-ras mutations in 1,2-dimethylhydrazine-induced colonic tumors: effects of supplemental dietary calcium and vitamin D deficiency. Cancer Res 1991;51:4305-9.

30. Bautista D, Obrador A, Moreno V, et al. Ki-ras mutation modifies the protective effect of dietary monounsaturated fat and calcium on sporadic colorectal cancer. Cancer Epidemiol Biomarkers Prev 1997;6:57-61.

31. Van der Meer R, Lapré JA, Govers MJAP, Kleibeuker JH. Mechanisms of the intestinal effects of dietary fats and milk products on colon carcinogenesis. Cancer Lett 1997;114:75-83.

32. Cats A, Kleibeuker JH, van der Meer R, et al. Randomized, double- blinded, placebo-controlled intervention study with supplemental calcium in families with hereditary nonpolyposis colorectal cancer. J Natl Cancer Inst 1995;87:598-603.

33. Lupton JR, Steinbach G, Chang WC, et al. Calcium supplementation modifies the relative amounts of bile acids in bile and affects key aspects of human colon physiology. J Nutr 1996;126:1421-8.

34. Alberts DS, Ritenbaugh C, Story JA, et al. Randomized, doubleblinded, placebo-controlled study of effect of wheat bran fiber and calcium on fecal bile acids in patients with resected adenomatous colon polyps. J Natl Cancer Inst 1996;88:81-92.

35. Lapré JA, De Vries HT, Termont DSML, Kleibeuker JH, De Vries EGE, Van der Meer R. Mechanism of the protective effect of supplemental dietary calcium on cytolytic activity of fecal water. Cancer Res 1993;53: 248-53.

36. Stern HS, Gregoire RC, Kashtan H, Stadler J, Bruce RW. Long-term effects of dietary calcium on risk markers for colon cancer in patients with familial polyposis. Surgery 1990;108:528-33.

37. Gregoire RC, Stern HS, Yeung KS, et al. Effect of calcium supplementation on mucosal cell proliferation in high risk patients for colon cancer. Gut 1989;30:376-82.

38. Alder RJ, McKeown-Eyssen G, Bright-See E. Randomized trial of the effect of calcium supplementation on fecal risk factors for colorectal cancer. Am J Epidemiol 1993;138:804-14.

39. Lipkin M, Newmark H. Effect of added dietary calcium on colonic epithelial-cell proliferation in subjects at high risk for familial colonic cancer. N Engl J Med 1985;313:1381-4.

40. Wargovich MJ, Isbell G, Shabot M, et al. Calcium supplementation decreases rectal epithelial cell proliferation in subjects with sporadic adenoma. Gastroenterology 1992;103:92-7.

41. Baron JA, Tosteson TD, Wargovich MJ, et al. Calcium supplementation and rectal mucosal proliferation: a randomized controlled trial. J Natl Cancer Inst 1995;87:1303-7.

42. Bostick RM, Fosdick L, Wood JR, et al. Calcium and colorectal epithelial cell proliferation in sporadic adenoma patients: a randomized, double-blinded, placebo-controlled clinical trial. J Natl Cancer Inst 1995; 87:1307-15.

43. Armitage NC, Rooney PS, Gifford K-A, Clarke PA, Hardcastle JD. The effect of calcium supplements on rectal mucosal proliferation. Br J Cancer 1995;71:186-90.

44. Peipins LA, Sandler RS. Epidemiology of colorectal adenomas. Epidemiol Rev 1994;16:273-97.

45. Dawson-Hughes B, Harris SS, Krall EA, Dallal GE. Effect of calcium and vitamin $\mathrm{D}$ supplementation on bone density in men and women 65 years of age or older. N Engl J Med 1997;337:670-6. 